DOI: 10.1002 /anie.201611409

Communication

\title{
Selective Arene Cleavage through Direct Insertion of Iridium into the Aromatic Ring
}

Martin Jakoobi, ${ }^{[a]}$ Dr. Nathan Halcovitch, ${ }^{[b]}$ Dr. George^^F.^^s. Whitehead, [a] Dr. Alexey^^G. Sergeev 0000-0003-1587-2517*[a]

[a] <orgDiv/>Department of Chemistry, <orgName/>University of Liverpool

<street/>Crown Street, <city/>Liverpool, <postCode/>L69 7ZD (<country/>UK)

E-mail: sergeev@liv.ac.uk

[b] <orgDiv/>Department of Chemistry, <orgName/>Lancaster University

<city/>Lancaster, <postCode/>2LA1 4YB (<country/>UK)

<pictid> Supporting information and the ORCID identification number(s) for the author(s) of this article can be found under:

<+><url>http://dx.doi.org/10.1002/anie.201611409</url>.

Nur die Schwachen überleben: Bei einer milden und selektiven Insertion eines Metallzentrums in einen Arenring spaltet das einfache Cp*Ir-Fragment starke aromatische C-C-Bindungen in Alkylarenen ohne Auswirkungen auf schwächere C-H- und C-CBindungen. Dies ist eine konzeptionell neue Art von Reaktivität, die wichtig für eine Reihe industrieller Prozesse sein könnte, wie die Herstellung von Chemikalien und Brennstoffen aus Kohle und pflanzlicher Biomasse. 
Arene

C-C-Aktivierung

Iridium

Metall-Metall-Wechselwirkungen

$n^{4}$-Arenkomplexe

Running mild: A mild and selective insertion of a metal center into the arene ring is reported. The simple Cp*Ir fragment cleaves strong aromatic $\mathrm{C}<\mathrm{C}->\mathrm{C}$ bonds in alkylarenes without affecting weaker $\mathrm{C}<\mathrm{C}->\mathrm{H}$ and $\mathrm{C}<\mathrm{C}->\mathrm{C}$ bonds. This work reveals a conceptually new type of reactivity that could be important for a range of industrial processes involving the generation of chemicals and fuel from coal and plant biomass.

$\mathrm{C}<\mathrm{C}->\mathrm{C}$ Activation

arenes

$\mathrm{C}<\mathrm{C}->\mathrm{C}$ activation

iridium

metal--metal interactions

$n^{4}$-arene complexes

We report an unprecedented selective cleavage of aromatic $\mathrm{C}<\mathrm{C}-$ $>C$ bonds through the insertion of well-defined iridium complexes into the aromatic ring of simple alkylarenes. The insertion occurs at $50--100^{\wedge}{ }^{\circ} \mathrm{C}$ without the activation of weaker $\mathrm{C}<\mathrm{C}->\mathrm{H}$ and $\mathrm{C}<\mathrm{C}->\mathrm{C}$ bonds and gives unique metallacycles in high yields. Key to the success of this approach is metalinduced deformation of the arene ring, which creates temporary ring strain and promotes direct and selective insertion of the metal into the otherwise inert arene ring $\mathrm{C}<\mathrm{C}->\mathrm{C}$ bonds. 
Many industrial processes on a multimillion tonne scale for the synthesis of organic chemicals from natural resources rely on the cleavage of aromatic $\mathrm{C}<\mathrm{C}->\mathrm{C}$ bonds, which are the strongest bonds found in aromatic hydrocarbons. [1] This transformation is facilitated by heterogeneous catalysts that typically require harsh conditions $\left(350--450^{\circ} \mathrm{C}\right)$ and suffer from poor selectivity that results from competing activation of other weaker $\mathrm{C}<\mathrm{C}->\mathrm{C}$ and $\mathrm{C}<\mathrm{C}->\mathrm{H}$ bonds found in aromatic molecules. ${ }^{[1 a, b]}$ More active soluble complexes can cleave an arene ring under milder conditions. However, only a few rare examples are known and in most cases the cleavage occurs with poor yields and involves prior chemical modification of the arene ring. ${ }^{[2]}$ In this context, Parkin and Sattler $<$ ? $><$ ? $>$ Ref. [3] also gives Walter and Tamm??<?><?>reported a remarkable metal insertion into the heteroarene ring of quinoxaline via an initial nitrogen-directed dehydrogenation (Figure^^1^A<figr1>). ${ }^{[2 a, \wedge 3]}$ Later, Hou et^^al. described intriguing cleavage of benzene and toluene on trinuclear titanium hydride clusters through partial hydrogenation, ring contraction, and metal insertion into the smaller ring (Figure^^1^B<xfigrl>). ${ }^{[2 b]}$ Alternatively, alkylarene cleavage can be promoted by a mixture of a metallacarborane and an excess of lithium, but the product yield is low. ${ }^{[2]}$ These reports indicate that despite significant recent progress in the activation of aromatic $\mathrm{C}<\mathrm{C}->\mathrm{C}$ bonds, the problem of direct and selective insertion of the metal center into the aromatic ring has yet to be solved.

Herein, we describe a direct and highly selective insertion of an iridium complex into the aromatic ring of industrially important alkylarenes (Figure^^ $1^{\wedge} \mathrm{C}<\mathrm{xfigr} 1>$ ). The 
insertion occurs exclusively into the arene-ring $\mathrm{C}<\mathrm{C}->\mathrm{C}$ bonds without affecting weaker $\mathrm{C}<\mathrm{C}->\mathrm{H}$ and $\mathrm{C}<\mathrm{C}->\mathrm{C}$ bonds, which highlights a conceptually new mode of reactivity that should be valuable for improving existing functionalizations of aromatic hydrocarbons and designing novel ones.

We discovered this unusual transformation while investigating the reactivity of rare $n^{4}$-arene iridium (I) complexes (Figure^^1<xfigrl>) as a platform for the selective functionalization of coordinated arenes. These $\eta^{4}$-arene complexes contain the arene ligand strongly coordinated to the metal center through four out of six ring carbon atoms. ${ }^{[4]}$ The uncoordinated part of the arene ring contains a double bond like the one in a cyclic alkene. More importantly, the $\eta^{4}-$ coordinated arene ring is bent and hence experiences steric ring strain that enhances its reactivity. As a result, such bent arenes have the potential to react as analogues of cyclic strained alkenes. An impressive example of this reactivity was demonstrated by Gladysz and co-workers in a rutheniumcatalyzed ring-opening metathesis polymerization of the $n^{4}-$ coordinated benzene in the cyclopentadienyl (Cp) iridium complex. ${ }^{[4 \mathrm{c}]}$ This work inspired us to investigate whether the reactivity of such "spring-loaded" $\eta^{4}$-coordinated arenes could trigger direct metal insertion into the arene ring ( Figure^^1<xfigr $1>$ ).

To realize this approach, we first focused on the synthesis of target $\eta^{4}$-arene pentamethylcyclopentadienyl (Cp*) iridium complexes from model arenes (Figure^^ $1^{\wedge} \mathrm{C}<\mathrm{xfigr} 1>$ ). As a first model arene, we chose symmetrical trimethylbenzene (mesitylene), which has one kind of aromatic $\mathrm{Csp}^{2}<\mathrm{C}->\mathrm{Csp}^{2}$ bond, 
as well as one kind each of weaker $\mathrm{Csp}^{2}<\mathrm{C}->\mathrm{H}$ and $\mathrm{Csp}^{3}<\mathrm{C}->\mathrm{H}$ bonds (Figure^^2<figr2>). Mesitylene was converted into the target $\eta^{4}$-mesitylene iridium complex 1 via the classical $\eta^{6}-$ arene complex 2 (Figure^^2<xfigr2>). The latter was obtained from the commercially available iridium chloride dimer $\left[\mathrm{Cp} * \mathrm{IrCl}_{2}\right]_{2}, \mathrm{AgBF}_{4}$, and mesitylene at room temperature in 98^\% yield. Like a typical $n^{6}$-arene complex, 2 contains a planar arene coordinated to the metal center through six carbon atoms as evidenced by $x-r a y<?>?>$ crystallography? $<?><?>$ data (Figure^^2<xfigr $2>$ ). Reduction of 2 with two equivalents of cobaltocene in benzene at room temperature gave the target $\eta^{4}-$ mesitylene iridium (I) complex 1 in 98^\% yield. Single-crystal $\mathrm{X}$-ray analysis of 1 revealed severe deformation of the coordinated arene, as evidenced by bending of the arene ring at an angle of $45^{\circ}$ and alternating $\mathrm{C}<\mathrm{C}->\mathrm{C}$ bond lengths in the ring (Figure^^2<xfigr $2>$ and Supporting information).

Upon heating 1 in $n$-hexane solution at $50^{\wedge}{ }^{\circ} \mathrm{C}$, we discovered the unexpected formation of the unusual binuclear complex 3 and free mesitylene as exclusive products (Figure^^2<xfigr2>). ${ }^{[6]}$ Complex 3 was isolated in 92^\% yield. As can be seen from the crystal structure (Figure^^2<xfigr $2>$ ), 3 is an eight-membered metallacycle that is a product of the insertion of a Cp*Ir<C->IrCp* fragment into the arene ring. The metal--metal bond length of $2.74^{\wedge} \AA$ is in agreement with an Ir $^{\text {II }}<\mathrm{C}->$ Ir $^{\text {II }}$ single bond. ${ }^{[7]}$ Each iridium atom in 3 forms one $\sigma$-bond with one of the vinyl fragments and one $\pi$-bond with another. We have not found any reported analogues of such iridium complexes in the literature, although related flyover complexes of cobalt and ruthenium have been proposed as 
intermediates in the catalytic trimerization of alkynes to arenes. ${ }^{[8]}$

Although the exact reason for this highly unusual reactivity of the $\mathrm{n}^{4}$-mesitylene complex is not clear, the $\mathrm{C}<\mathrm{C}-$ $>C$ bond cleavage could be triggered by release of the induced ring strain in the bent arene ring. As mentioned above, the bent arene ring in $n^{4}$-complexes can be regarded as an analogue of strained alkenes, such as norbornadiene, which is known to undergo insertion of a metal into the $\mathrm{C}<\mathrm{C}->\mathrm{C}$ bond. ${ }^{[9]}$ In line with this idea, the corresponding $\eta^{6}$-complex $\mathbf{2}$, which contains the non-strained, planar arene ring, remained unreactive under the same reaction conditions. The release of the ring steric strain_k?>?>ring strain? $<?<?>$ in 1 can also explain the high selectivity of metal insertion into the ring $\mathrm{Csp}^{2}<\mathrm{C}->\mathrm{Csp}^{2}$ bond without affecting weaker $\mathrm{Csp}^{2}<\mathrm{C}->\mathrm{Csp}^{3}, \mathrm{Csp}^{2}<\mathrm{C}->\mathrm{H}$, and $\mathrm{Csp}^{3}<\mathrm{C}->\mathrm{H}$ bonds (Figure^^2<xfigr $2>$ ).

Encouraged by this exciting result, we explored the scope of this process by probing the reactivity of arenes that are important products of fossil fuel processing: benzene, toluene, and xylenes (BTX arenes). ${ }^{[1 b]}$ Our next target was mxylene, which has one methyl group less than mesitylene and has three different arene-ring $\mathrm{C}<\mathrm{C}->\mathrm{C}$ bonds available for cleavage (Figure^^3<figr $3>$ ). The arene was converted into the $n^{4}-m-x y l e n e$ iridium (I) complex 4 via the corresponding $\eta^{6}-$ cationic iridium (III) intermediate in 93^\% overall yield (Figure^^3<xfigr3>). Note that $\mathbf{4}$ is the first example of an $\eta^{4}-$ arene complex with an unsymmetrically substituted arene. Such complexes can potentially exist as three regioisomers. The ${ }^{1} \mathrm{H}^{\wedge} \mathrm{NMR}$ spectrum of $\mathbf{4}$ confirmed the presence of all three 
isomers in solution, with $\mathbf{4}^{\wedge}$ a being the dominant one ( Figure^^3<xfigr $3>$ ).

Heating the m-xylene complex 4 in $n$-hexane solution at $50^{\wedge}{ }^{\circ} \mathrm{C}$ led to complete consumption of all three regioisomers ${ }^{[10]}$ and quantitative formation of the ring-cleavage product 5 and free m-xylene in an equal ratio according to the ${ }^{1} \mathrm{H}^{\wedge}{ }^{\wedge} \mathrm{NMR}$ data (Figure^^3<xfigr $3>$ ). Intriguingly, $\mathrm{C}<\mathrm{C}->\mathrm{C}$ cleavage in the $\mathrm{m}-$ xylene complex 4 occurred more slowly than in the more sterically hindered mesitylene complex 1 (Figure^^2<xfigr2> and Figure^^3<xfigr $3>$ ). Metallacycle product 5 was isolated as a single regioisomer in 94^\% yield and its structure was unambiguously confirmed by NMR spectroscopy and X-ray

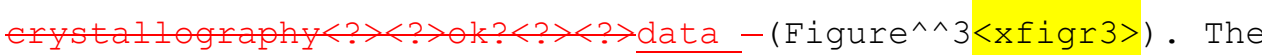
quantitative formation of 5 indicates exclusive cleavage of aromatic $\mathrm{C}<\mathrm{C}->\mathrm{C}$ bonds in the presence of weaker $\mathrm{Csp}^{2}<\mathrm{C}->\mathrm{Csp}$ and benzylic $\mathrm{C}<\mathrm{C}->\mathrm{H}$ bonds in the coordinated m-xylene. It also demonstrates that cleavage of the aromatic $\mathrm{C}<\mathrm{C}->\mathrm{C}$ bonds occurs with high regioselectivity: out of three different kinds of ring $\mathrm{C}<\mathrm{C}->\mathrm{C}$ bonds, the metal exclusively activates the least sterically hindered bond (Figure^^3<xfigr $3>$ ). This result highlights the unparalleled chemo- and regioselectivity of the arene cleavage by the IrCp* fragment.

Next, we probed the ring cleavage of toluene by the Cp*Ir fragment (Figure^^4<figr $4>$ ). The target $\eta^{4}$-complex 6 was obtained from toluene and $\left[\mathrm{Cp} * \mathrm{IrCl}_{2}\right]_{2}$ in two steps with 93^\% total yield. Like its m-xylene analogue, 6 exists as a mixture of three regioisomers (Figure^^4<xfigr $4>$ ). Upon heating in $n-$ hexane, complex 6 underwent arene ring scission, but the reaction occurred more slowly than with the m-xylene complex 4 
and required a higher temperature of $100^{\wedge}{ }^{\circ} \mathrm{C}$ for complete conversion (Figures^^3<xfigr3> and 4<xfigr4>). The cleavage gave the metallacycle 7 in $68^{\wedge} \circ{ }^{1} \mathrm{H}$ NMR yield-as measure by NMPR. ${ }^{[11]}$ Although three regioisomers of 7 were produced, isomer 7^a was formed with 71^\% selectivity, thus indicating that the iridium again preferentially inserts into the least sterically hindered aromatic $\mathrm{C}<\mathrm{C}->\mathrm{C}$ bond (Figure^^ $4<\mathrm{xfigr} 4>$ ).

Finally, to test whether our approach would enable ring scission of non-substituted benzene, we conducted thermolysis of the corresponding $\eta^{4}$-benzene complex [Cp* $\operatorname{Ir}\left(\eta^{4}-\right.$ benzene) ] (8). Unexpectedly, the reaction did not form any ring-cleavage product, even upon prolonged heating at $100^{\wedge} \mathrm{C}$ for $24^{\wedge} \wedge \mathrm{h}$; instead a mixture of a few unidentified species was formed. [12] The reactivity of the coordinated arenes in the observed $\mathrm{C}<\mathrm{C}->\mathrm{C}$ bond cleavage reactions decreases with a decrease in the degree of substitution, from the most reactive mesitylene through m-xylene and toluene to the least reactive benzene. The higher reactivity of the more substituted arenes dramatically contrasts with the preferential insertion of the metal into the least sterically hindered arene ring $\mathrm{C}<\mathrm{C}->\mathrm{C}$ bond and requires further mechanistic investigation.

We propose three potential mechanistic pathways for this unusual arene cleavage (Figure^^5<figr $5>$ ). Pathway^^A involves direct insertion of the metal into the $\eta^{4}$-coordinated arene in 9 to give transient iridacycloheptatriene 10. [13] This intermediate would then react with another molecule of $\mathbf{9}$ to give the bimetallic flyover product $11 .^{[14]}$ Pathway ${ }^{\wedge} B$ proceeds through formation of the triple-decker arene complex 12, which undergoes subsequent cleavage of the arene ring and formation 
of the iridium--iridium bond to form 11. Although stable iridium complexes such as 12 are not known, triple-decker complexes have been described for other group^^9 metals such as cobalt ${ }^{[15]}$ and rhodium. ${ }^{[16]}$ Finally, pathway^^C involves formation of the bimetallic complex 13, which has a metal-metal bond and a bridged $<$ ? $><$ ? $>$ bridging? $<$ ? $><$ ? $>\mu-n^{3}: n^{3}$-arene (Figure^^5<xfigr5>). Again, the corresponding diiridium species have not yet been reported, but similar $\mathrm{I} r \mathrm{C}->\mathrm{Rh}$ and Rh $<\mathrm{C}->\mathrm{Rh}$ complexes with less bulky Cp ligands have been characterized. ${ }^{[17]}$ The bridged<? $><$ ? $>$ bridging? $<$ ? $><$ ? $>$ arene ligand in these species is heavily distorted and adopts a boat conformation that is made up from two allylic fragments linked by weakened and strained sigma bonds. We hypothesize that such bonds in the corresponding Ir<C->Ir species 13 would be even weaker because of more pronounced steric repulsion between the bulkier Cp* ligands and $\mathrm{Culd}^{*}$ therefore would be more prone to undergo $\mathrm{C}<\mathrm{C}->\mathrm{C}$ oxidative addition to give the insertion product.

To detect any potential intermediates in this arenecleavage process, we monitored the thermolysis of complex 1 in n-hexane at $50^{\wedge}{ }^{\circ} \mathrm{C}$ by ${ }^{1} \mathrm{H}^{\wedge}{ }^{\wedge} \mathrm{NMR}$ - spectroscopy, but no intermediate species was observed at any conversion of the starting complex. This result might suggest rate-limiting formation of unstable intermediate species 10, 12, or 13, followed by rapid formation of the final metallacycle 11. Further studies to identify potential intermediates and elucidate the mechanism of this process are ongoing in our laboratory.

In conclusion, we have demonstrated an unprecedented strategy for selective, direct cleavage of aromatic rings 
under mild conditions by the simple and widely used organometallic fragment Cp*Ir. This strategy exploits metalinduced strain in the arene rings to enable a previously elusive selective insertion of the metal into aromatic $\mathrm{C}<\mathrm{C}->\mathrm{C}$ bonds in the presence of weaker $\mathrm{C}<\mathrm{C}->\mathrm{H}$ and $\mathrm{C}<\mathrm{C}->\mathrm{C}$ bonds that remain unaffected. Given the high yields and selectivity of this approach, we anticipate that this work will help to improve existing arene functionalizations, as well as in the development of alternative arene functionalizations through $\mathrm{C}<\mathrm{C}->\mathrm{C}$ activation and further elaboration of the induced-ringstrain concept.

\section{Acknowledgements}

We gratefully acknowledge the University of Liverpool and the Royal Society (grant RG140673) for financial support and the EPSRC UK National Mass Spectrometry Facility at Swansea University for HR-MS analyses. We also thank Prof. Jianliang Xiao and Dr. Konstantin Luzyanin for constructive comments.

\section{Conflict of interest}

The authors declare no conflict of interest. $\left\langle\right.$ litl $><$ lit_a $>\left\langle j n l>G \cdot{ }^{\wedge} B\right.$. McVicker, M. Daage, M.^^s. Touvelle,

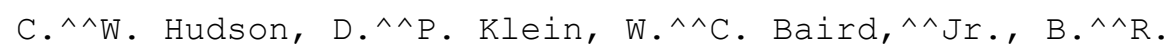

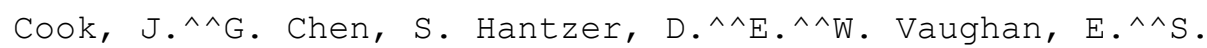
Ellis, $0 . \wedge^{\wedge} C$. Feeley, J. Catal. 2002, 210, 137--148</jnl>; $<$ lit_b $><$ book $>$ K. Weissermel, H.-J. Arpe, Industrial organic chemistry, 4th^^ed., Wiley-VCH, Weinheim, 2003</book>; $<$ lit_c $>$ jnl $>$ Y. Traa, Chem. Commun. 2010, 46, 2175--

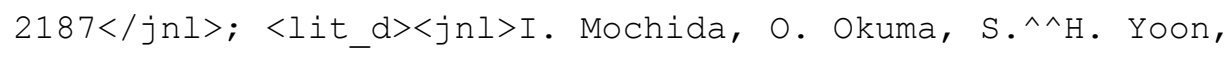

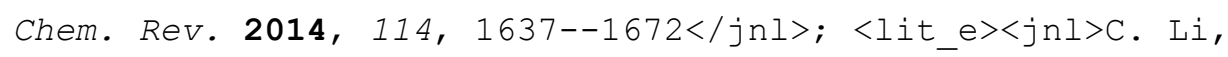


X. Zhao, A. Wang, G.^^W. Huber, T. Zhang, Chem. Rev. 2015, 115, 11559--11624</jnl>.

$<$ lit2 $><$ lit_a $><j n l>A$. Sattler, G. Parkin, Nature 2010, 463, 523--526</jnl>; <lit_b><jnl>S. Hu, T. Shima, Z. Hou, Nature

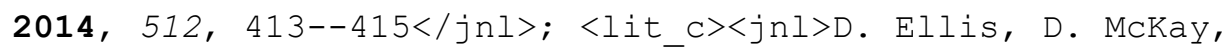
S.^^A. Macgregor, G.^^M. Rosair, A.^^J. Welch, Angew. Chem. Int. Ed. 2010, 49, 4943--4945; Angew. Chem. 2010, 122, $5063--5065</ j n l>$.

$<$ itt $3><j n l>M . \wedge \wedge D$. Walter, M. Tamm, Angew. Chem. Int. Ed. 2010, 49, 3264--3266; Angew. Chem. 2010, 122, 3334--3336</jnl>.

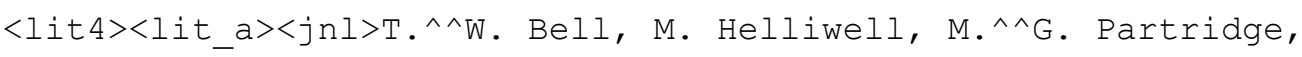
R.^^N. Perutz, Organometallics 1992, 11, 1911--1918</jnl>; <lit_b><jnl>J. Müller, T. Akhnoukh, P.^^Е. Gaede, A. Guo, P. Moran, K. Qiao, J. Organomet. Chem. 1997, 541, 207-$217</ j n l>$; <lit_C $>\langle j n l>P . \wedge \wedge D$. Zeits, T. Fiedler, J.^^A. Gladysz, Chem. Commun. 2012, 48, 7925--7927</jnl>.

<lit5><book>Y.-R. Luo, Comprehensive handbook of chemical bond energies, 1st^^ed., CRC Press, Boca Raton, 2007</book>. <lit6>Reactions conducted in $\mathrm{CH}_{2} \mathrm{Cl}_{2}, \mathrm{THF}$, mesitylene, or benzene gave lower yields of the insertion product owing to the formation of side products.

<lit $7><$ book $>$ C.^^A. Murillo, in Multiple bonds between metal atoms, 3rd^^ed. (Eds.: F.^^A. Cotton, C.^^A. Murillo, R.^^A. Walton), Springer, New York, 2005, pp.^^447-$487</$ book $>$.

$<$ lit $8><$ lit_a $><j n l>D . \wedge \wedge S$. Perekalin, E.^^A. Trifonova, V.^^V. Novikov, Y.^^V. Nelyubina, A.^^R. Kudinov, J. Organomet. Chem. 2013, 737, 21--25</jnl>; <lit_b $><j n l>R$. Giordano, E. 
Sappa, G. Predieri, Inorg. Chim. Acta 1995, 228, 139-$146</ j n l>$.

<lit9><jnl>y. Ohki, H. Suzuki, Angew. Chem. Int. Ed. 2000, 39, 3463--3465; Angew. Chem. 2000, 112, 3605--3607</jnl>.

<lit10>The relative ratio of the isomers remained constant up to 90^\% conversion, which might suggest rapid isomerisation of the three isomers before the cleavage (see Figure^^s1 in the Supporting Information).

$<$ lit11>The reaction occurred with the formation of a few iridium-containing side products that do not show aromatic signals in the ${ }^{1} \mathrm{H}^{\wedge} \wedge \mathrm{NMR}$ spectrum (see the supporting Information).

<lit12>The ${ }^{1} \mathrm{H}^{\wedge} \wedge \mathrm{NMR}$ spectrum of the obtained mixture does not show vinylic and aromatic signals characteristic for the flyover and $\mathrm{Ph}<\mathrm{C}->\mathrm{Ir}<\mathrm{C}->\mathrm{H}$ (Ph=phenyl) oxidative addition products, respectively. According to mass spectrometry data, the structure of one of the products is consistent with the triple-decker [Cp*Ir(benzene) IrCp*] (see the Supporting Information).

$<$ lit13><lit_a $>$ This step could be regarded as a reverse of the final steps of catalytic trimerisation of alkynes to arenes, in which complexes similar to 9 and 10 have been proposed as potential intermediates. See Refs.^^[13b--d]; $<$ lit_b $><j n l>C$. Bianchini, K.^^^G. Caulton, C. Chardon, M.^^L. Doublet, O. Eisenstein, S.^^A. Jackson, T.^^J. Johnson, A. Meli, M. Peruzzini, W.^^^E. Streib, A. Vacca, F. Vizza, Organometallics 1994, 13, 2010--2023</jnl>; $\langle$ lit_c $>\langle j n l>C .-H$. Guo, H. $-S$. Wu, M. Hapke, H. Jiao, J. Organomet. Chem. 2013, 748, 29--35</jnl $>$; $\langle$ lit_d $>\langle$ book $>$ K. 
Tanaka, in Arene chemistry: reaction mechanisms and methods for aromatic compounds, 1st^^ed. (Ed.: J. Mortier), Wiley, Hoboken, 2016, pp.^^587--614</book>.

<lit14>The insertion of a single iridium metal center into the arene ring in 9 to give the iridacycloheptatriene 10 is likely to be thermodynamically unfavorable. Indeed, DFT calculations reported for the insertion of the related CpIr fragment into the coordinated benzene ring in the $\operatorname{CpIr}\left(n^{4}-\right.$ benzene) complex showed that this process is thermodynamically uphill by $30^{\wedge} \wedge \mathrm{kcal}^{\wedge} \mathrm{mol} \mathrm{l}^{<\mathrm{M}->1}$ (see Ref.^^[13c]). We suppose that the iridium insertion in our case is thermodynamically feasible because of formation of a strong iridium--iridium bond that stabilizes the final flyover metallacycle 11 and makes it a "thermodynamic sink" for the whole process.

<lit15><lit_a><jnl>J.^^J. Schneider, U. Denninger, O.

Heinemann, C. Kruger, Angew. Chem. Int. Ed. Engl. 1995, 34, 592--595; Angew. Chem. 1995, 107, 631--634</jnl>;

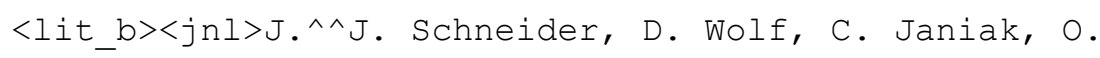
Heinemann, J. Rust, C. Krüger, Chem. Eur. J. 1998, 4, 1982$-1991</ j n l>$.

$<$ lit16><jnl>P.^^H. Budzelaar, N.^^N. Moonen, R. de^^Gelder, J.^^M. Smits, A.^^W. Gal, Chem. Eur. J. 2000, 6, 2740-$2747</ j n l>$.

<lit17><jnl>J. Müller, P.^^E. Gaede, K. Qiao, J. Organomet.

Chem. 1994, 480, 213--220</jnl>. 
Manuscript received: November 21, 2016

Revised: December 25, 2016

Final Article published: <?><?>

Figure^^1 Approaches for the cleavage of arene $\mathrm{C}<\mathrm{C}->\mathrm{C}$ bonds by transition metals.

Figure^^2 Iridium-mediated cleavage of mesitylene: strategy, selectivity, and crystal structures of intermediates.

$[a]^{\wedge}$ Reaction conditions: $\left[\mathrm{Cp} \mathrm{IrCl}_{2}\right] 2\left(0.2^{\wedge} \wedge \mathrm{mmol}\right), \mathrm{AgBF}_{4}$

$\left(1.0^{\wedge} \mathrm{mmol}\right)$, mesitylene $\left(0.40^{\wedge \wedge} \mathrm{mL}, 4.3^{\wedge \wedge} \mathrm{mmol}\right)$, acetone $\left(6^{\wedge} \wedge \mathrm{mL}\right), 24^{\wedge}{ }^{\circ} \mathrm{C}, 16^{\wedge} \wedge \mathrm{h} .[\mathrm{b}]^{\wedge \wedge}$ Yield of isolated product for each step at full conversion of the starting complex. [c]^^^The yield was based on Ir assuming that one mmole of $\left[\mathrm{Cp}^{*} \mathrm{IrCl}_{2}\right]_{2}$ gives two mmoles of 2. [d]^^^Reaction conditions: 2 $\left(0.37^{\wedge} \mathrm{mmol}\right), \mathrm{Cp}_{2} \mathrm{Co}\left(0.74^{\wedge \wedge} \mathrm{mmol}\right)$, benzene $\left(3.5^{\wedge} \wedge \mathrm{mL}\right), 24^{\wedge}{ }^{\circ} \mathrm{C}$,

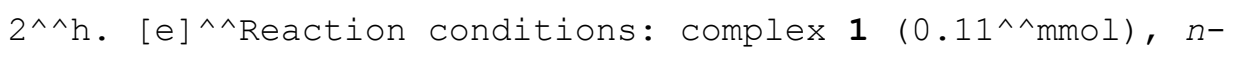
hexane $\left(0.8^{\wedge} \mathrm{mL}\right), 50^{\wedge}{ }^{\circ} \mathrm{C}, 22^{\wedge} \wedge \mathrm{h} .[\mathrm{f}]^{\wedge} \wedge^{\wedge}$ The yield was based on Ir assuming that two mmoles of 1 give one mmole of 3 and one mmole of mesitylene. [g]^^Estimated bond dissociation energies. ${ }^{[5]}$.

Figure^^3 Iridium-mediated cleavage of m-xylene: strategy, regioselectivity, and crystal structure of 5. [a]^^Reaction conditions: $\left[\mathrm{Cp} \mathrm{IrCl}_{2}\right]_{2}\left(0.125^{\wedge \wedge} \mathrm{mmol}\right), \mathrm{AgBF}_{4}\left(0.50^{\wedge} \mathrm{mmol}^{\prime}, \mathrm{m}-\right.$ xylene $\left(0.60^{\wedge} \mathrm{mL}, 3.2^{\wedge} \mathrm{mmol}\right)$, acetone $\left(2^{\wedge} \wedge \mathrm{mL}\right), 24^{\wedge}{ }^{\circ} \mathrm{C}, 16^{\wedge} \wedge \mathrm{h}$.

$\left[\mathrm{b}^{\wedge} \wedge\right.$ Reaction conditions: $\left[\mathrm{Cp} * \operatorname{Ir}\left(\mathrm{n}^{6}-m-\mathrm{xylene}\right)\right]\left(\mathrm{BF}_{4}\right)_{2}$

$\left(0.20^{\wedge} \mathrm{mmol}\right), \mathrm{Cp}_{2} \mathrm{Co}\left(0.40^{\wedge} \mathrm{mmol}\right)$, benzene $\left(2^{\wedge} \wedge \mathrm{mL}\right), 24^{\wedge} \mathrm{C}, 2^{\wedge}{ }^{\wedge} \mathrm{h}$. [c]^^Total yield of isolated product based on Ir for two steps ([a] and [b]) at full conversion of the starting materials. [d]^^The ratio of isomers was determined by ${ }^{1} \mathrm{H}^{\wedge} \wedge \mathrm{NMR}$. 
[e]^^Reaction conditions: complex $4\left(0.09^{\wedge}{ }^{\wedge} \mathrm{mmol}\right), n$-hexane $\left(0.8^{\wedge} \mathrm{mL}\right), 50^{\wedge}{ }^{\circ} \mathrm{C}, 48^{\wedge} \wedge \mathrm{h} .[\mathrm{f}]^{\wedge}$ Isolated yield. The yield was based on Ir assuming that two mmoles of $\mathbf{4}$ give one mmole of $\mathbf{5}$ and one mmole of m-xylene.

Figure^^4 Iridium-mediated cleavage of toluene: strategy and regioselectivity. [a]^^^Reaction conditions: $\left[\mathrm{Cp}^{\star} \mathrm{IrCl}_{2}\right]_{2}$ $\left(0.125^{\wedge} \mathrm{mmol}^{\prime}\right), \mathrm{AgBF}_{4}\left(0.50^{\wedge \wedge} \mathrm{mmol}\right)$, toluene $\left(0.40^{\wedge} \wedge \mathrm{mL}\right.$, $\left.3.8^{\wedge \wedge} \mathrm{mmol}\right)$, acetone $\left(3^{\wedge \wedge} \mathrm{mL}\right), 24^{\wedge}{ }^{\circ} \mathrm{C}, 2^{\wedge \wedge} \mathrm{h} .[\mathrm{b}]^{\wedge \wedge}$ Reaction conditions: $\left[\mathrm{Cp} * \operatorname{Ir}\left(\eta^{6}-\right.\right.$ toluene $\left.)\right]\left(\mathrm{BF}_{4}\right)_{2}\left(0.26^{\wedge} \wedge \mathrm{mmol}\right)$, benzene $\left(2^{\wedge} \wedge \mathrm{mL}\right), 24^{\wedge}{ }^{\circ} \mathrm{C}, 2^{\wedge \wedge} \mathrm{h} .[\mathrm{c}]^{\wedge}{ }^{\wedge} \mathrm{Total}$ yield of isolated product for two steps ([a] and [b]) at full conversion of the starting materials. [d]^^^The ratio of isomers was determined by ${ }^{1} \mathrm{H}^{\wedge}{ }^{\wedge} \mathrm{NMR}$. $\left[e{ }^{\wedge} \wedge\right.$ Reaction conditions: complex $6\left(0.21^{\wedge} \wedge m m o l\right), n$-hexane $\left(2^{\wedge} \wedge \mathrm{mL}\right), 100^{\wedge}{ }^{\circ} \mathrm{C}, 48^{\wedge} \wedge \mathrm{h} .[\mathrm{f}]^{\wedge}{ }^{\wedge} \mathrm{NMR}$ yield based on Ir assuming that two mmoles of 6 give one mmole of 7 and one mmole of toluene.

Figure^^5 Outline of potential mechanistic pathways for the cleavage of the aromatic ring in the $n^{4}$-arene Ir complexes. 